\title{
Approach to Building and Implementing Business Intelligence Systems
}

\author{
Celina M. Olszak and Ewa Ziemba \\ University of Economics, Katowice, Poland \\ olszak@ae.katowice.pl ewa.ziemba@ae.katowice.pl
}

\begin{abstract}
Abstract: The article aims at describing processes of building Business Intelligence (BI) systems. Taking the BI systems specifics into consideration, the authors present a suggested methodology of the systems creation and implementation in organisations. The considerations are focused on objectives and functional areas of the $\mathrm{BI}$ in organisations. Hence, in this context the approach to be used while building and implementing the BI involves two major stages that are of interactive nature, i.e. BI creation and BI "consumption". A large part of the article is devoted to presenting objectives and tasks that are realised while building and implementing BI.
\end{abstract}

Key words: Business Intelligence, methodology of BI construction, designing BI, business decision-making, knowledge management

\section{Introduction}

Socio-economic reality of contemporary organisations has made organisations face some necessity to look for instruments that would facilitate effective acquiring, processing and analysing vast amounts of data that come from different and dispersed sources and that would serve as some basis for discovering new knowledge.

For long time management information systems (MIS) have been supporting organisations in their different tasks. However, today many IT systems have undergone significant depreciation. Hitherto existing management information systems (i.e. MIS, DSS, ES, EIS) have not always met decision makers' expectations, such as:

- making decisions under time pressure;

- monitoring competition;

- possessing such information on their organisations that includes different points of view; and

- carrying out constant analyses of numerous data and consider different variants of organisation performance.

Material published as part of this publication, either on-line or in print, is copyrighted by the Informing Science Institute. Permission to make digital or paper copy of part or all of these works for personal or classroom use is granted without fee provided that the copies are not made or distributed for profit or commercial advantage AND that copies 1) bear this notice in full and 2) give the full citation on the first page. It is permissible to abstract these works so long as credit is given. To copy in all other cases or to republish or to post on a server or to redistribute to lists requires specific permission and payment of a fee. Contact Publisher@InformingScience.org to request redistribution permission.
They simply do not handle integration of different, dispersed and heterogenic data well, they cannot interpret such data in any broad contexts effectively and they are not capable of sufficient discovering new data interdependencies (Bui, 2000; Gray, \& Watson, 1998). Reasons are to be found in improper 
techniques of data acquisition, analysis, discovery and visualisation (Figure 1).

In order to be able to react quickly to changes that take place on the market, organisations need management information systems that would make it possible to carry out different cause and effect analyses of organisations themselves and their environments (Power, 2001).

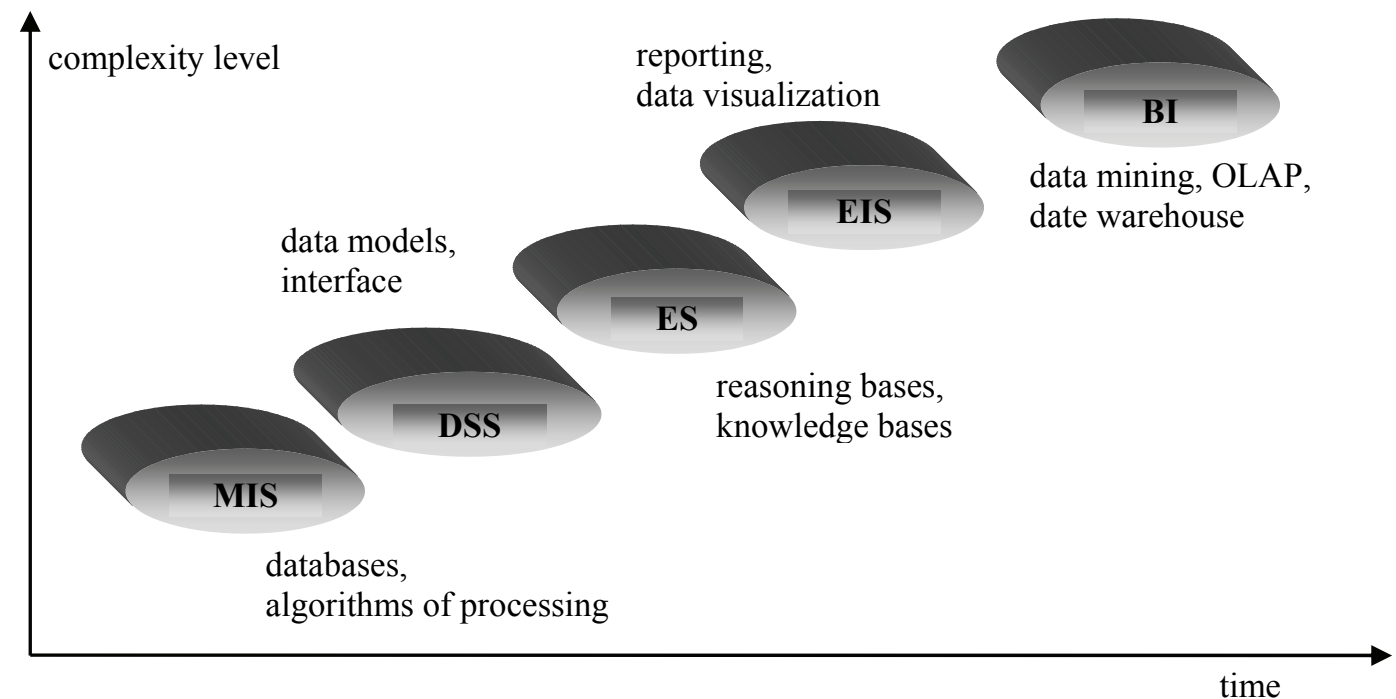

Figure 1. Development of management information systems.

Source: (Olszak, \& Ziemba, 2004).

Business Intelligence (BI) systems provide a proposal that faces needs of contemporary organisations. Main tasks that are to be faced by the BI systems include intelligent exploration, integration, aggregation and a multidimensional analysis of data originating from various information resources. Systems of a BI standard combine data from internal information systems of an organisation and they integrate data coming from the particular environment e.g. statistics, financial and investment portals and miscellaneous databases. Such systems are meant to provide adequate and reliable up-to-date information on different aspects of enterprise activities.

As the first research results show, the BI systems in question contribute to improvement and transparency of information flows and knowledge management and they also enable organisations to (Kalakota, \& Robinson, 1999; Liautaud, \& Hammond, 2002; Moss, \& Alert, 2003):

- follow profitability of their products sold;

- analyse expenditures;

- monitor corporate environments; and

- discover business anomalies and frauds.

Recent years have witnessed numerous discussions on the Business Intelligence issues including OLAP techniques, data mining or data warehouses. However, little attention has been paid so far to questions of creating and implementing BI in organisations. Such questions are rarely analysed in categories of solutions that would facilitate effective decision making and strategic thinking. There is no a sufficient number of guidelines informing how to create systems that might be used as examples of authentic symbiosis of IT and management processes. 
With reference to the above formulated research problem, the article has been assumed to aim at suggesting methodology of creating and implementing BI Systems. Realisation of this objective in different companies, in authors' humble opinion, will largely contribute to diminishing some gap in supporting processes of decision making by means of BI.

\section{Objectives of BI systems}

BI systems may be analysed from different perspectives. Decision makers and organisations should predominantly associate BI with organisational implementation of specific philosophy and methodology that would refer to working with information and knowledge, open communication, knowledge sharing along with the holistic and analytic approach to business processes in organisations. BI systems are assumed to be solutions that are responsible for transcription of data into information and knowledge and they also create some environment for effective decision making, strategic thinking and acting in organisations (Figure 2). Value of BI for business is predominantly expressed in the fact that such systems cast some light on information that may serve as the basis for carrying out fundamental changes in a particular enterprise, i.e. establishing new cooperation, acquiring new customers, creating new markets, offering products to customers (Chaudhary, 2004; Olszak, \& Ziemba, 2004; Reinschmidt, \& Francoise, 2002 ).

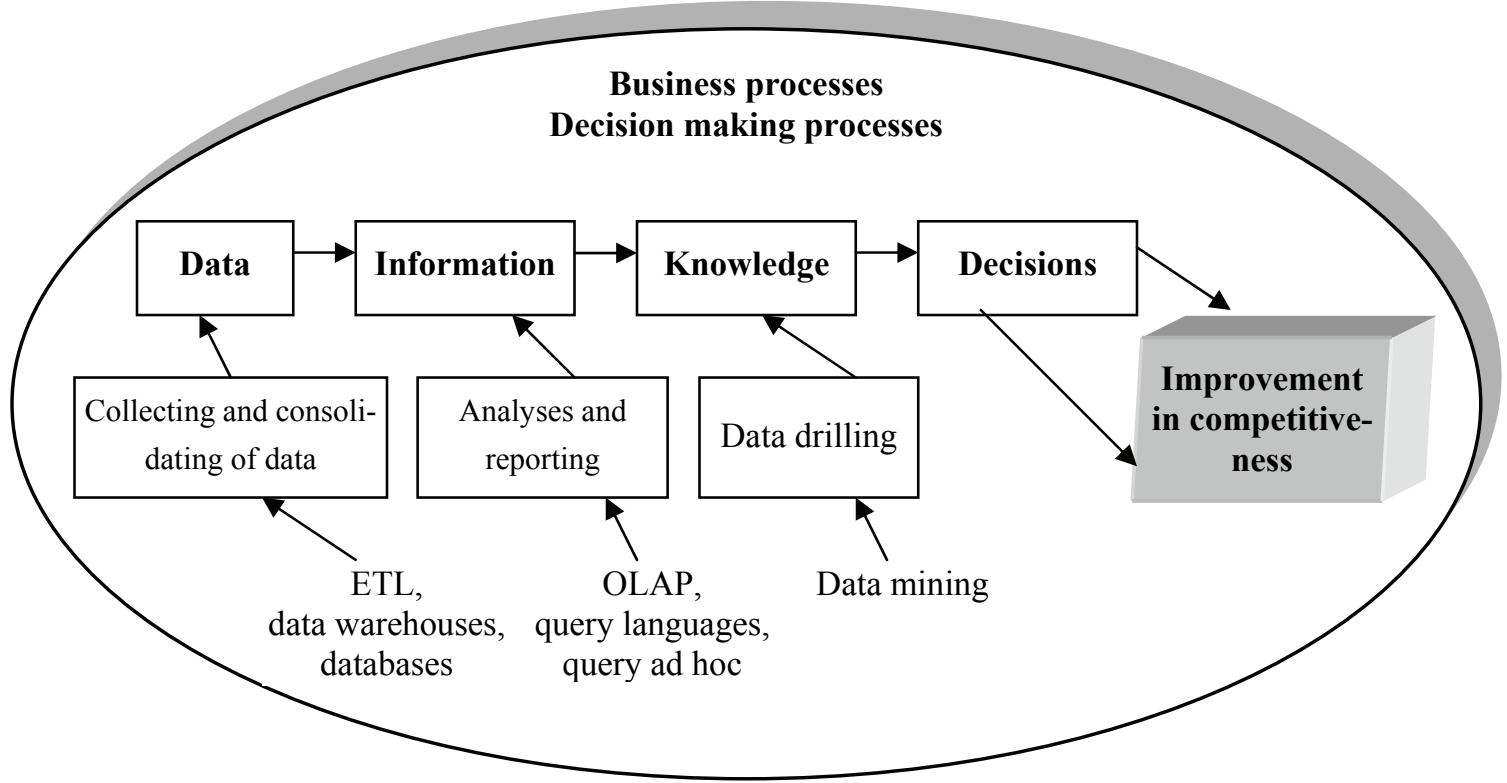

Figure 2: The role of BI systems in decision making.

Source: own elaboration.

BI differs from MIS (i.e. DSS, EIS, and ES) in, first of all, their wider thematic range, multivariate analysis, semi-structured data originating from different sources and multidimensional data presentation (Gray, 2003).

It is assumed that BI may support decision making on all levels of management regardless of the level of their structuralisation (Olszak, \& Ziemba, 2003). On the strategic level, BI makes it possible to set objectives precisely and to follow realisation of such established objectives. BI allows for performing different comparative reports, e.g. on historical results, profitability of particular offers, effectiveness of distribution channels along with carrying out simulations of development or forecasting future results on the basis of some assumptions. 
On the tactical level, BI Systems may provide some basis for decision making within marketing, sales, finance, capital management, etc. The systems allow for optimising future actions and for modifying organisational, financial or technological aspects of company performance appropriately in order to help enterprises realise their strategic objectives more effectively.

With reference to the operational level, BI Systems are used to perform ad hoc analyses and answer questions related to departments' ongoing operations, up-to-date financial standing, sales and co-operation with suppliers, customers, etc.

Observation of different cases of BI Systems allows for stating that the systems in question may support data analyses and decision making in different areas of organisation performance, particularly including the following (Hsu, 2004; Olszak, \& Ziemba, 2003):

- financial analyses that involve reviewing of costs and revenues, calculation and comparative analyses of corporate income statements, analyses of corporate balance sheet and profitability, analyses of financial markets and sophisticated controlling;

- marketing analyses that involve analyses of sales receipts, sales profitability, profit margins, meeting sales targets, time of orders, actions undertaken by competitors, stock exchange quotations;

- customer analyses that concern time of maintaining contacts with customers, customer profitability, modelling customers' behaviour and reactions, customer satisfaction, etc.;

- production management analyses that make it possible to identify production 'bottlenecks' and delayed orders, thus enabling organizastions to examine production dynamics and to compare production results obtained by departments or plants, etc.;

- logistic analyses that enable to identify partners of supply chain quickly;

- analyses of wage related data including wage component reports made with reference to the type required, reports made from the perspective of a given enterprise, wage reports distinguishing employment types, payroll surcharges, personal contribution reports, analyses of average wages, etc.; and

- personal data analyses that involve examination of employment turnover, employment types, presentation of information on individual employee's personal data, etc.

According to the opinions voiced by the Gartner Group, enterprises use BI systems mainly for corporate management, optimisation of customer relations, monitoring of business activities, reporting, planning and decision making support on all levels of management. The most spectacular results have already been observed while running promotional campaigns, anticipating sales and customer behaviours, creating loyalty policies and investigating anomalies and frauds (Olszak, \& Ziemba, 2006).

From a technical perspective, BI systems offer an integrated set of tools, technologies and software products that are used to collect heterogenic data from dispersed sources in order to integrate and analyse data to make it commonly available. BI tasks implicate a technological structure of the BI systems. The structure in question consists of the following modules:

- tools to extract, transform and load data (ETL, Extraction-Transformation-Load tools) they are mainly responsible for data transfer from transaction systems and the Internet to data warehouses;

- data warehouses - they provide some room for thematic storing of aggregated and already analysed data; 
- analytic tools (OLAP, On-Line Analytical Processing) - they let users access, analyse and model business problems and share information that is stored in data warehouses;

- data mining tools - they enable their users to discover various patterns, generalisations, regularities and rules in data resources;

- tools for reporting and ad hoc inquiring - they allow for creating and utilising different synthetic reports; and

- presentation layer - applications including graphic and multimedia interfaces whose task is to provide users with information in a comfortable and accessible form.

To recapitulate, the most important components of the BI technological infrastructure consist of key information technologies that are related with data acquisition along with storing (ETL tools and data warehouses) and information technologies potential that mainly refers to versatile analyses of data along with presentation of data (OLAP techniques and data mining).

\section{Suggested Methodology of Building BI Systems}

Building and implementing BI systems require organisations to have some culture of working with information and information technologies, which is related to:

- thorough and ongoing research into organisations' informational needs (present and future);

- authentic co-operation of the users involved (i.e. decision makers and operational personnel) with organisations' IT departments and knowledge management centres;

- information sharing; and

- abilities to interpret analyses and use such analyses in management properly.

Suggesting the methodology of building and implementing BI systems, the authors have benefited from sound business practices set by enterprises that succeed in building BI systems. Any general model to be suggested may be a set of guidelines and some kind of a pattern for organisations that want to use any BI system. The model in question pays particular attention to the role of end users in the whole life cycle of the BI systems including the phase of the BI usage in particular. Parameterisation of the BI system carried out by its user is required for its correct performance. Such parameterisation involves providing repositories with knowledge (employees, customers, suppliers or co-operators). Using BI systems will succeed in business only when their users keep:

- identifying and modelling knowledge;

- monitoring and modifying data repositories;

- creating their own analyses and reports;

- learning how to interpret results and ask sophisticated questions; and

- improving business and decision making on the ongoing basis.

All the above has to be manifested in the system performance. Taking into account significant influence users have on the BI system performance allows for suggesting two major iterative stages in the approach to building and creating the systems in question, i.e. (compare: Dresner, Buytendijk, Linden, Friedman, Strange, Knox, \& Camn, 2002): 
- creation of BI; and

- use ("consumption") of BI.

$\mathrm{BI}$ creation is the most time consuming and this stage requires the greatest part of financial and manpower resources in the whole BI life cycle. BI creation consists of numerous stages including in particular:

- definition of the BI undertaking, i.e. determination of the BI system development strategies;

- identification and preparation of source data;

- $\quad$ selection of BI tools;

- designing and implementing of BI; and

- discovering and exploring new informational needs and other business applications and practices.

The BI "consumption" stage is predominantly associated with end user application. The stage shows its major role in popularising and promoting practices that are related to data analyses and BI systems. This stage may be divided into several different steps to be taken at the discretion of users and according to their needs or tasks to be faced. The steps mainly include the following:

- logistic analyses that enable to identify partners of supply chain quickly;

- access, monitoring and analyses of facts;

- development of alternative decisions;

- division and co-operation; and

- change in the effect of company performance.

\section{Strategy of the BI System Development}

Undertaking realisation of BI systems in organisations, it is first necessary to determine a general vision of such systems. The systems also have to be related to business objectives. This stage involves specifying informational needs of organisations, simultaneously paying attention to key IT decision makers and specialists. Ranking of informational needs (carried out on the basis of their importance) allows for highlighting e.g. indexes that are important while realising business strategies (Chaudhary, 2004).

It is necessary to remember that applying of BI systems in organisations makes sense when companies involved are not interested in passive recording of different events only. Such companies ought to focus their attention on interpretation of different events in different wider contexts, e.g. when it is more important to understand customers' expectations and preferences than to find out the amount of income obtained. BI systems should closely correspond to business objectives of enterprises. Therefore, the most important motives that support implementation of BI systems in enterprises may include the following (Kalakota, \& Robinson, 1999; Liautaud, \& Hammond, 2002; Rasmussen, Goldy, \& Solli, 2002):

- transitioning from instinct and intuition decision making to objectivism that is based on the analysis of facts, indexes, balanced score cards, managerial cockpits, etc.;

- forecasting enterprise development along with customers' and suppliers' behaviour; 
- matching operational activities with realisation of strategic objectives (measuring development in the realisation of strategies, monitoring of business process effectiveness, matching budgets and investments with corporate strategies);

- implementing standards that are used as the basis for repetitive, regular and cyclical business processes within organisations;

- unifying informational transfers in order to make them more transparent and unifying roles of individuals who participate in decision making processes;

- rapid detecting of information that deviates from commonly accepted standards and procedures and that suggests some possibilities that new threats will emerge (dishonest customers, inflated material or energy usage, etc.);

- shortening time that is necessary to analyse information, and decreasing a number of participants who are involved in analysing and processing of information; and

- automatic and rapid reporting and preparing of plans and forecasts.

At this stage, it is necessary to find areas and business processes that will first undergo different analyses and explorations. Analysing this process in enterprises that have already implemented BI systems, it is possible to note that it was natural for the enterprises in question to start with finance. Then, marketing, customer relations management and logistics followed. As far as sectors are concerned, enterprises that pioneered BI implementation mainly include banks and insurance institutions that were subsequently followed by telecommunications, power engineering, transportation, trade companies and production enterprises.

Observing general trends in companies that show BI initiatives, it is possible to assume that the development of the majority of BI is characterised by a top-down approach, i.e. firstly, decision making by the board and top management is supported and then lower levels of management are involved. At this stage, it is necessary to decide whether a particular BI solution is planned to be implemented in one department and if it is supposed to cover a selected scope of enterprise functioning or whether a potential solution is to be of complex nature, thus integrating different aspects of activities undertaken by enterprises. Translating this situation into the data warehouse context may provide an answer to the question if a particular enterprise is going to create individual data marts (that are subsequently going to be integrated in a corporate data warehouse), or whether the enterprise in question will immediately take up building an integrated data warehouse that would cover the enterprise's different departments. The data marts oriented approach is supported by a less demanding scope of a project and - as a result - by faster effects to be obtained. However, it is possible to observe some future difficulties while integrating different individual data marts in one corporate data warehouse.

Formulating general requirements for potential BI systems, it is also worth considering whether, for instance, such systems should work online, whether they ought to be directed at symmetric exploration of Internet websites or at advanced forecasting analyses, etc. At this stage, available sources of information are not taken into consideration. The objective is rather to identify general business needs, even if it turns out that supporting such needs might be difficult or hardly possible.

\section{Identification and Preparation of Data for the BI System}

At the stage of identifying and preparing data, it is necessary to specify sources of data that may be used to support business needs. Such specification requires finding internal sources (intellectual resources, information technology resources, paper files, etc.) and external ones (concentrated on customers, suppliers, shareholders, etc) along with verifying reliability of the sources 
and a form of transformations that the sources in question will have to undergo so that they could be subject to further analyses. Realisation of this stage calls for remarkable help provided by decision makers, operational workers, IT departments, departments of knowledge management and strategic customers.

At this stage, it is necessary to diagnose all information systems and databases used in a given enterprise (simple applications that are based on dbf files, Access or sophisticated ERP systems). While carrying out such a diagnosis, it is worth following several important instructions (Błotnicki, \& Wawrzynek, 2006):

- find data that are to be found in the IS and that are not important from the perspective of the analyses carried out;

- find relations between data in different information systems;

- describe the logical structure of data that are to be found in the system: much attention should be paid not only to their structure in the base but also to the relation with business processes described;

- find places that allow for generating errors in data (a possibility that data are inconsistent); and

- find limits of IS applicability (which data cannot be reported out of IS, e.g. due to erroneous logic of source bases).

At this stage, it may turn out that a lot of data are hidden or just inaccessible, and that it is necessary to use numerous informal sources. A huge amount of valuable data that are necessary for analytic reports may be hidden, e.g. in the Internet resources. While searching for such data, it is suggested to take advantage of the following methods:

- manual searching: documents are directly downloaded by a particular system user;

- automatic searching and downloading of HTML documents by means of appropriate software; and

- queries: using browsers that search through indexes.

Contents mined this way may provide interesting information. Processes of mining depend on the data obtained. When data get filtered and are made homogenous, they may be directly transferred to databases. ETL techniques are responsible for this process to the large extent. In order to mine information from semistructured and unstructured sources, techniques of the so-called 'wrappers' along with text processing methods may prove useful (Poul, Gautman, \& Balint, 2003).

Apart from text identification, it is recommended to carry out reliability, up-to-datedness, precision and consistency assessments. It is also necessary to find out whether data of the BI system should be provided systematically or with some minimal delay or periodically.

\section{Selection of BI Tools}

Selection of a BI tool may turn out to be a difficult task. At present companies offer a wide range of products beginning from simple reporting technologies up to sophisticated BI platforms. While choosing a BI tool, it is necessary - like in the case of purchasing other IS - to take the following criteria into consideration: functionality, complexity of solutions, and compatibility. It is also necessary to remember that organisation's informational needs will evolve. Therefore, BI tools should be up-to-date enough to meet enterprise's expectations in a few years to come. 
At this stage, good market knowledge of BI is required. Today BI products may be found in different segments of the IT market (Ilczew, 2006). Providers of MRP II and ERP systems more and more frequently equip their products with BI modules (e.g. SAP, Oracle or Microsoft), thus wishing to make their products more dynamic and analytical. OLAP techniques and data mining have also been implemented in database systems (Oracle, Microsoft or IBM). Planning and budgeting belong to another segment of the IT market that uses BI techniques. Additionally, it has to be mentioned that there is a group of providers that offer BI solutions in a highly specialised area and usually on a very high level of customer need satisfaction. Such products often include best practices for a particular sector along with some future solutions. One cannot forget about open source solutions that are more and more frequently available on the market.

In the BI sector - similarly as in case of other IT sectors - it is possible to observe some processes of consolidating providers - purchasing products or expanding products by means of functionalities that are offered by the best providers in a given category. Hence, it is necessary to consider whether a given enterprise ought to purchase products and technologies from one provider or if such an enterprise should follow a principle of selecting the best products in a given category (e.g. the best tools for OLAP, ETL, etc.) sold by different providers. In the former case, enterprises are guaranteed integration of particular products and a similar interface. However, it has to be taken into account that not all solutions are going to be of the highest possible quality. Package purchase of products frequently involves discounts, which is quite important for enterprises. On the other hand, purchasing products from several providers may lead to delegating responsibility for particular module performance to other providers. It is also more difficult to obtain larger discounts while purchasing technologies that come from different providers. There is also some other possibility - purchase of a ready to use solution instead of a particular technology. In this situation, it is necessary to learn more about capacities of a given application and then consider whether such an application meets enterprise's needs and whether there are some elements that the application in question should be subsequently provided with. Providing an enterprise with BI products of an open source type is another possibility. Examples of complimentary or open source products may be provided by Sygate Analyst (a tool used for data visualisation), Agata Reports (a reporting tool), Oracle Application Express (environment for building web applications), and cockpit for the management in open source ERP Compiere, Business Intelligence Reporting Tool for Eclipse or Mondrian OLAP Server. Some providers of BI products use free databases. For instance, Business Objects uses a complimentary database called MySQL (Poul, Gautman, \& Balint, 2003).

\section{Designing and Implementing the BI System}

A scale of effort undertaken at the stage of designing and implementing BI varies. Such effort predominantly depends on the system complexity and the level of its popularity. However, in the majority of cases, creation of a customised BI application requires a lot of time. The time required is spent not only on designing individual interfaces but also on making sure that the whole BI application is logical and consistent.

Another important stage of designing BI involves building a data warehouse that is supposed to perform two functions: of a repository for further analyses, and of a base for the BI system (Inmon, 1992). This process has to be carried out in compliance with the following rules (Błotnicki, \& Wawrzynek 2006; Hackathorn, 1998):

- setting a scope of data stored in the IS that are important from a perspective of a given organisation;

- defining interconnections between data that are to be found in different systems and that are of the same importance. As a result of such activities, a set of data will be created and 
the data in question will allow for designing a target database (a repository) where data from source bases will be sent; and

- creating a design of a data warehouse that serves as a basis for loading a BI system. Such a design should be created in order to provide easy configuration of database related reporting and querying mechanisms. The design is suggested to aim at reaching a model of 'a star' or 'snowflake' that simplifies further implementation of data warehouse mechanisms including OLAP or data mining.

In order to make sure that a data warehouse is systematically updated to include data that come from e.g. transaction systems, it is necessary to create mechanisms of data import (Meyer, 2001). Such mechanisms ought to allow for importing all data and should enable users to perform incremental import that only requires processing of data that have reached source systems since the last import. Incremental import does not burden source systems and mechanisms of data processing. Mechanisms of data transfer simultaneously perform a controlling function that is responsible for data consistency. In many cases the mechanisms in question allow for finding inconsistencies and errors at the stage of implementation. Import procedures are created so that they could record erroneous data to be then transferred to a repository base, which enables to correct the data in the place of their origination, and - subsequently - to transfer such data to the base.

A created data warehouse ought to be the basis for building modules within reports and reporting. It is necessary to provide for a few or at least two groups of reports. The former should cover predefined reports that are systematically updated by potential users. Such a group should also provide more advanced users with some possibilities to create their own reports according to their individual needs. The latter type of reports and reporting involves reports that result from unexpected individual needs that concern details to be found in data.

Experience shows that - sooner or later - enterprises will need to use multidimensional analyses (Rasmussen et al., 2002), which means that a BI solution ought to aim at OLAP modules (that let users mine and view data in different perspectives) and data mining (that contributes to better understanding of customers' preferences, nature of such preferences, supply chain, geographical impacts, etc.) (Grossman, 1998; Kantardzic, 2002; Perkowitz, \& Etzioni, 1999). Depending on the specifics and needs of organisations, it is possible to consider carrying out analyses that are responsible for, inter alia (Olszak, \& Ziemba, 2006):

- examining customers' profitability and their lifetime value;

- verifying importance of parameters;

- $\quad$ segmenting and profiling of customers;

- monitoring customers' loyalty and withdrawals;

- checking customers' maintenance;

- finding similarities;

- $\quad$ studying frauds;

- $\quad$ studying marketing campaigns;

- and carrying out cross sales.

A layer of data presentation is an important element of BI systems. With reference to the above, it is necessary to pay much attention to designing an interface. Development of interfaces is clearly influenced by two tendencies. The former involves application of a spreadsheet as an interface. For instance, Oracle provides business users of its Oracle $10 \mathrm{~g}$ database with a possibility to use 
the Microsoft Excel spreadsheet. The former tendency involves using internet browsers. In such a situation, a BI application is not confined to users in a given enterprise only - it may be taken advantage of by external partners as well (Ilczew, 2006).

\section{Exploring and Discovering New Informational Needs}

The stage of exploration and discovery of new informational needs is of critical importance for the whole cycle of building any BI. Implemented BI environment casts new light on the role of information and competencies in an enterprise and on business relations and interdependencies. At this stage, new informational needs emerge and new methods of information management are created. Using notions of iterative designing and rapid application development (RAD), it is possible to observe that the $\mathrm{BI}$ environment obtained is a prototype that should serve as the basis for evaluation and commencement of a new cycle of building a BI application (Dresner et al., 2002). The exploration and discovery stage requires remarkable co-operation of representatives of IT departments with a centre for knowledge management along with end users whose all innovativeness and willingness to experiment with data are of much importance.

\section{BI “consumption” stage}

Depending on tasks to be undertaken by users, a process of using different data repositories along with ready to use analyses starts. Data are compared and interpreted. This stage requires users to show much initiative. Depending on emerging needs, users should create author analyses and reports and be able to ask relevant questions and interpret results to be obtained.

Analyses of different facts may reveal alternative methods of solving a particular task and some other possibilities of optimising numerous activities. A selection of a final decision to be made frequently requires consultations with other employees and decision makers.

Analyses of the already mentioned questions and answers should cover co-operation and communication of all individuals who participate in decision making of an enterprise. Such behaviour involves some necessity to eliminate problems related to, inter alia, privacy and data appropriation in an enterprise.

Work with information and tools used to analyse and explore data allows for carrying out fundamental changes in a decision making process. Changes in enterprise performance involves, inter alia, looking for new forms of co-operation or outsourcing, new markets and business partners, etc. (Linoff, \& Berty, 2002; Srivastava, 2003).

Accomplishment of the last stage of the cycle of building and using BI systems does not mean that all BI related problems are dealt with in a given enterprise. As it has already been mentioned, the cycle in question is of iterative nature, thus being some kind of a loop that continuously requires carrying out more and more analyses of informational needs, re-evaluation of already existing solutions and their modifications, optimisations and adjustment.

\section{Conclusions}

Each methodology of information system designing and implementing should be characterised by certain canons. In case of BI systems particular attention ought to be paid to the following issues:

- BI systems should be rapidly implemented, which is quite difficult because such systems are specific for each enterprise. Although basing on standard components shortens time required to build $\mathrm{BI}$, each implementation necessitates adjusting of a particular system to specific requirements of an enterprise. While choosing ready to use BI solutions, it is necessary to be very careful; 
- BI solutions ought to be flexible. As soon as business changes, organisations should adjust their BI systems to new conditions;

- BI systems ought to be independent of their hardware and software platforms. Hence, it is recommended that a system of multidimensional analyses should co-operate with different bases (e.g. DB/2, Oracle, MS SQL Server or Informix) and work in already tested and commonly applied operation systems (e.g. Windows NT, Unix or OS/400). Such solutions will allow for better adjusting the system in question to information technology related infrastructure of an enterprise;

- While creating BI systems, it should be necessary to pay some attention to the fact that there are different information technology systems in organisations (e.g. transaction systems, MRP II, ERP, etc.);

- BI solutions have to be scaleable. Flexibility and open architecture allow for easy expansion of the system. It is necessary in a situation when there are new informational needs or when an amount of information to be processed remarkably increases); and

- BI systems should be based on modern technologies. It is necessary to pay much attention to solutions provided by household names of the computer industry. Only then, it is possible to expect stability and reliability of purchased technologies.

BI systems pose a chance for the effective management of an enterprise. However, they require analysts', designers' and users' high business, information and organisational culture. Skills to identify, model (in the processes and organisation structures) and share knowledge constitute only some factors that determine a correct development of the BI systems.

\section{References}

Błotnicki, A., \& Wawrzynek, Ł. (2006). Od porządkowania danych do Business Intelligence - jak uświadomiona wiedza staje się elementem konkurencyjności organizacji. [From sorting data to business intelligence - How does conscious knowledge become an element of corporate competitiveness?] In A. Binsztok, \& K. Perechuda (Eds.), Koncepcje, modele i metody zarzadzania informacja $i$ wiedza. Wrocław: AE.

Bui, T. (2000). Decision support systems for sustainable development. In G. E. Kersten, Z. Mikolajuk, \& A. Gar-on Yeh (Eds.), Decision support systems for sustainable development. A resource book of methods and applications. Kluwer Academic Publishers.

Chaudhary, S. (2004). Management factors for strategic BI success. In Business intelligence in digital economy. Opportunities, limitations and risks. IDEA Group Publishing.

Dresner, H. J., Buytendijk, F., Linden, A., Friedman, T., Strange, K. H., Knox, M., \& Camn, M. (2002). The business intelligence center: An essential business strategy. Gartner Research.

Gray, P. (2003). Business intelligence: A new name or the future of DSS. In T. Bui, H. Sroka, S. Stanek, \& J. Goluchowski (Eds.), DSS in the uncertainty of the Internet age. Katowice: University of Economics.

Gray, P., \& Watson, H. (1998). Decision support in the data warehouse. Prentice Hall.

Grossman, R. (1998). Supporting the data mining process with the next generation data mining systems. Enterprise System Journal.

Hackathorn, R. D. (1998). Web farming for the data warehouse. Morgan Kaufmann.

Hsu, J. (2004). Data mining and business intelligence: Tools, technology and applications. In M. Raisinghani (Ed.), Business intelligence in the digital economy. London: Idea Group Publishing. 
Ilczew, P. (2006). Podejście biznesowe do wdrażania Business Inteligence. [Business approach to implementing business intelligence.] In J. Kisielnicki (Ed.), Informatyka w globalnym świecie. Warszawa: Wydawnictwo PJWST.

Inmon, W. H. (1992). Building the data warehouse. New York: J. Wiley.

Kalakota, R., \& Robinson, M. (1999). E-business: Roadmap for success. Addison-Wesley.

Kantardzic, M. (2002). Data mining: Concepts, models, methods and algorithms. New York: J. Wiley.

Liautaud, B., \& Hammond, M. (2002). E-business intelligence. Turning information into knowledge into profit. New York: McGraw-Hill.

Linoff, G. S. \& Berry, M. J. A. (2002). Mining the Web: Transforming customer data into customer value. New York: J. Wiley.

Meyer, S. R. (2001, June 1). Which ETL tool is right for you? DM Review Magazine.

Moss, L. T., \& Alert, S. (2003). Business intelligence roadmap - The complete project lifecycle for decision support applications. Addison-Wesley.

Olszak, C. M., \& Ziemba, E. (2003). Business intelligence as a key to management of an enterprise. Proceedings of Informing Science and IT Education Conference, 2003. Retrieved December 1, 2005 from http://proceedings.informingscience.org/IS2003Proceedings/docs/109Olsza.pdf

Olszak, C. M., \& Ziemba, E. (2004). Business intelligence systems as a new generation of decision support systems. Proceedings PISTA 2004, International Conference on Politics and Information Systems: Technologies and Applications. Orlando: The International Institute of Informatics and Systemics.

Olszak, C. M., \& Ziemba, E. (2006). Business intelligence systems in the holistic infrastructure development supporting decision-making in organizations. Interdisciplinary Journal of Information, Knowledge and Management, 1, 47-58. Retrieved December 1, 2006 from http://ijikm.org/Volume1/IJIKMv1p047-058Olszak19.pdf

Perkowitz, M., \& Etzioni, O. (1999). Adaptive web sites: Conceptual cluster mining. Proceedings of the 16th Joint National Conference on Artificial Intelligence. Stockholm.

Poul, S., Gautman, N., \& Balint, R. (2003). Preparing and data mining with Microsoft SQL Server 2000 and analysis services. Addison-Wesley.

Power, D. (2001). Supporting decision-makers: An expanded framework. Proceedings of the Informing Science and IT Education Conference. Retrieved December 1, 2006 from http://proceedings.informingscience.org/IS2001Proceedings/pdf/PowerEBKSupp.pdf

Rasmussen, N., Goldy, P. S., \& Solli, P. O. (2002). Financial business intelligence. Trends, technology, software selection, and implementation. John Wiley \& Sons.

Reinschmidt, J., \& Francoise, A. (2000). Business intelligence certification guide. IBM, International Technical Support Organization.

Srivastava, J., \& Cooley, R. (2003). Web intelligence: Mining the Web for actionable knowledge. Journal on Computing, 15. 


\section{Biographies}

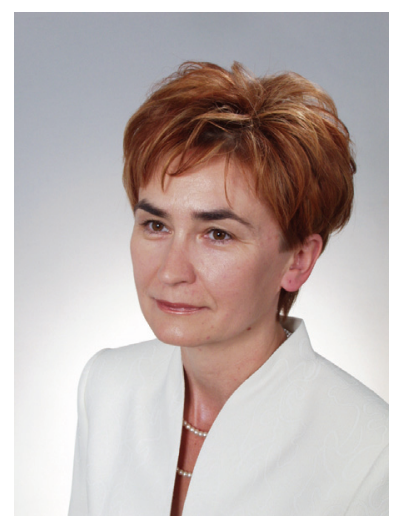

C. M. Olszak is a professor of Business Information Systems at University of Economics in Katowice. She holds MA in Information Systems from Technical University in Wrocław and $\mathrm{PhD}$ in Economics from University of Economics in Katowice.

Her special interests include Business Intelligence Systems, data warehouse, Decision Support Systems, knowledge management, ebusiness, multimedia and Internet technology.

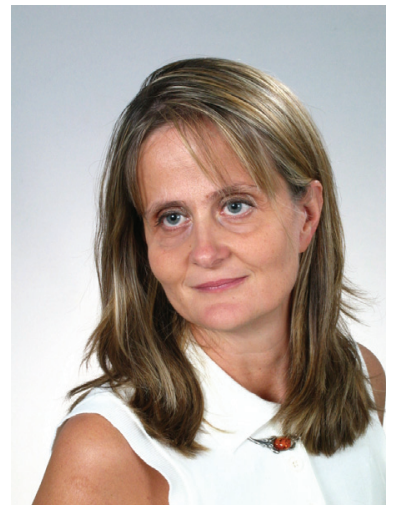

E. Ziemba is an associate professor of Business Information Systems at University of Economics in Katowice. She holds MA in Cybernetics and Computer Science from University of Economics in Katowice and $\mathrm{PhD}$ in Economics from University of Economics in Katowice.

Her special interests include Knowledge Management Systems, corporate portals, Decision Support Systems, e-business and Internet technology. 